\title{
Correction to: First report of Alternaria alternata causing post-harvest brown spot of Citrus reticulata Blanco cv. 'Kinnow' in Pakistan
}

\author{
Anam Moosa ${ }^{1,2} \cdot$ Ayaz Farzand $^{1,3} \cdot$ Shahbaz Talib Sahi ${ }^{2} \cdot$ Sajid Aleem Khan ${ }^{2} \cdot$ Muhammad Naveed Aslam ${ }^{1}$. \\ Tanvir Ahmad ${ }^{4} \cdot$ Ambreen Maqsood $^{1} \cdot$ Muhammad Shafique $^{3}$
}

Published online: 16 August 2021

○ Società Italiana di Patologia Vegetale (S.I.Pa.V.) 2021

\section{Correction to: Journal of Plant Pathology https://doi.org/10.1007/s42161-021-00924-z}

The original article was published not accrediting one of the co-authors to their corresponding affiliations. The original article has been corrected.
Publisher's Note Springer Nature remains neutral with regard to jurisdictional claims in published maps and institutional affiliations.

The original article can be found online at https://doi.org/10.1007/ s42161-021-00924-z.

Ayaz Farzand

ayaz.farzand@uaf.edu.pk

1 Department of Plant Pathology, The Islamia University of Bahawalpur, Bahawalpur, Pakistan

2 Department of Plant Pathology, University of Agriculture, Faisalabad, Pakistan

3 University of Agriculture Faisalabad, Sub-Campus Burewala-Vehari, Faisalabad, Pakistan

4 Chinese Academy of Agricultural Sciences/ Key 8 Laboratory of Agro-Products Quality and Safety Control in Storage and Transport Process 9, Ministry of Agriculture and Rural Affairs, Institute of Food Science and Technology, Beijing 100193, China 